\title{
A prospective comparison between clinical outcome and open- configuration magnetic resonance defecography findings before and after surgery for symptomatic rectocele
}

\author{
M. Hübner*, F. Hetzer*, D. Weishaupt†, D. Hahnloser*, P.-A. Clavien* and N. Demartines* \\ *Department of Visceral Surgery and Transplantation and †Department of Radiology, University Hospital, Zürich, Switzerland
}

Received 27 November 2005; accepted 8 January 2006

\begin{abstract}
Background The correlation between clinical symptoms and anatomical findings by conventional imaging is poor in patients with rectoceles. The aim of this prospective study was to assess and to correlate symptomatic changes after anterior levatorplasty with morphologic changes visualized by magnetic resonance defecography (MRD).
\end{abstract}

Method Fourteen women with a median age of 57 (range 37-83) accepted to participate. Seven of 14 had previous hysterectomy. Patients underwent MRD before surgery and again 6 months postsurgery. Pre- and postoperative symptoms and quality of life (QoL) (Eypasch) were assessed. Faecal and urinary incontinence were graded (Wexner- / Hanley-score).

Results The median Eypasch-score improved from 90 (range 38-106) to 106 (range 29-133) after surgery $(P=0.016)$. Similarly, the Wexner-score ameliorated from 8 (range $0-20$ ) to 4.5 (range $0-18 ; P=0.02$ ).
Seven patients described new dyspareunia postoperatively. The median follow up was 16.5 months (range 9-45). The median rectocele size decreased from $37 \mathrm{~mm}$ (range $30-48$ ) preoperatively to $12 \mathrm{~mm}$ (range $0-42$ ) postoperatively $(P=0.004)$. Furthermore, enteroceles were corrected and pelvic floor descent was significantly reduced after surgery. Only the clinical symptom of incomplete evacuation strongly correlated with the respective radiological finding of contrast dye trapping $(R h o=0.822 ; P=0.001)$.

Conclusion Anterior levatorplasty improved QoL in patients with symptomatic rectocele. Postsurgical correction of rectocele is accurately documented by MRD. Only moderate correlation between morphologic and clinical improvements was observed.

Keywords Magnetic resonance defecography, rectocele, anterior levatorplasty, quality of life

\section{Introduction}

A rectocele is a frequent form of pelvic organ prolapse, but its pathophysiology and impact on the symptoms remain unclear [1-3]. The majority of patients with rectocele are asymptomatic as small rectoceles can be found in up to $80 \%$ of healthy volunteers [4]. Moreover, other anorectal pathologies such as enteroceles and intussusceptions are frequent in symptomatic patients with rectocele [3]. As a result controversy arises over what represents a pathological rectocele.

Predisposing factors for a rectocele include age, menopause, parity and obesity [5]. The presence and

Correspondence to: Nicolas Demartines, Department of Visceral Surgery and Transplantation, University hospital of Zurich, Rämistrasse 100, 8091 Zürich, Switzerland.

E-mail: nicolas.demartines@usz.ch importance of a thinned recto-vaginal septum for the pathogenesis of a rectocele is controversial $[2,3]$ and pelvic muscular activity seems to have an important role in diminishing the recto-vaginal pressure gradient [6]. Clinical presentation is variable and includes constipation $(75-100 \%)$, pain $(12-70 \%)$, incontinence $(30 \%)$ and the need for manually assisted evacuation (digitation; 20$75 \%)$ [3].

The clinical diagnosis of a rectocele [1] can be confirmed by conventional defecography. However, sensitivity and specifity are observer-dependent and vary in the range of $91-100 \%$ and $58-100 \%$ respectively [7]. Furthermore, the correlation between the radiological findings and the clinical symptoms is poor $[3,8,9]$.

Magnetic resonance defecography (MRD) in a sitting position permits accurate and physiological assessment of anorectal morphology and function without exposing the patient to radiation [10]. In contrast to conventional 
defecography, MRD allows adjacent structures to be visualized in the three compartments [11,12] and enteroceles are diagnosed with a high accuracy of up to $100 \%$ [3]. Today, the value of MRD in pre- and postoperative assessment of symptomatic rectoceles has not yet been prospectively investigated.

First-line treatment for patients with a rectocele is usually conservative and consists of stool regulation, pelvic floor rehabilitation, local oestrogen and pessaries [2]. Indications for a surgical repair are still controversial and based mainly on severity of symptoms. Various transvaginal, endo-anal, transperineal or laparoscopic surgical techniques have been described to strengthen the recto-vaginal septum $[2,3,13]$. The success rates of these procedures range between $71 \%$ and $92 \%[3,13-15]$. Little has been reported about either the quality of life (QoL) before and after surgery or the correlation between anatomical repair and functional outcome.

The aims of this study were to prospectively assess anterior levatorplasty for symptomatic rectocele evaluating pre- and postoperative symptoms, QoL and MRD findings and to correlate clinical and radiological findings.

\section{Patients and methods}

\section{Study design}

Prospective clinical study of all patients undergoing anterior levatorplasty for symptomatic rectocele including pre- and postoperative MRD. The study was approved by the institutional review board and a written informed consent was obtained from every patient.

\section{Patients}

From January 2001 to January 2004, an anterior levatorplasty was performed in 16 symptomatic females with significant rectoceles, defined as measuring $>2 \mathrm{~cm}$ in sagittal diameter [16]. Fourteen patients with a median age of 57 (range 37-83) accepted the offer to be included in this prospective clinical study. Twelve of them $(86 \%)$ had at least one vaginal delivery and seven (50\%) had a previous hysterectomy, none of them presented with neurological impairment.

\section{Clinical assessment}

Pre- and postoperative clinical symptoms were collected prior to and 6 months after the operation. Faecal and urinary incontinence were assessed with the Wexner- [17] and the Hanley-score [18], respectively. QoL was graded by a validated QoL questionnaire (Eypasch) [19]. All patients underwent MRD prior to and again 6 months after surgery.

\section{MR defecography}

Magnetic resonance defecography was performed using a super conducting open-configuration MR system (Signa SP; General Electrics Medical systems, Milwaukee, Wisconsin, USA) in a sitting position [10]. Prior to MR imaging, the patient's rectum was filled with $300 \mathrm{ml}$ of a synthetic stool consisting of mashed potato starch mixed with $1.5 \mathrm{ml}$ of gadopentate dimeglumine $(377 \mathrm{mg} / \mathrm{ml})$ (Magnevist ${ }^{\circledR}$; Schering AG, Berlin, Germany), producing a gadolinium concentration of $2.5 \mathrm{mmol} / \mathrm{l}$. After filling the rectum, the patient was placed upright on a wooden chair, which fits into the magnet rings. A multiphase fast Tl-weighted spoiled gradient-recalled echo (SPGR) sequence (TR, $22.2 \mathrm{~ms}$; TE, $10.6 \mathrm{~ms}$ ) was performed in the midsagittal plane of the anal canal with an image update every $2 \mathrm{~s}$. MR images were obtained with the patient sitting at rest, maximally squeezing the sphincter and during evacuation. All images acquired during the different positions were formatted into a cine loop presentation to enable assessment of the dynamic of rectal emptying and of pelvic floor movement. Overall imaging time including patient preparation varied between 15 and $20 \mathrm{~min}$. Two independent observers blinded for clinical findings reviewed images.

Analysis of MR defecographies was performed in a standardized manner using a workstation (Advantage Windowing Workstation; GE Medical Systems Europe, Buc, France). Both MR images and cine loops were analysed with regard to structural abnormalities of the pelvic floor including anterior rectoceles, enteroceles, internal and external rectal prolapses, rectal descents (descent of the posterior compartment), cystoceles (descent of the anterior compartment) and vaginal vault (or any part of the remaining cervix in case of hysterectomy) descents (descent of the middle compartment). All measurements were taken at rest, at sphincter contraction, as well as at the end of defecation, whereas the largest measured distance was taken for further analysis. A rectocele was defined as a rectal protrusion beyond the expected margin of the rectal wall (imaginary line extended upward through the anal canal). Depending on the remaining contrast dye after defecation, rectoceles were classified as complete or incomplete evacuating. The pubococcygeal line (PCL), joining the inferior border of the symphysis with the last coccygeal joint in the midline sagittal MR image served as a reference line for measuring the position of any of the three compartments of the pelvic floor as well as to measure the depth of any enterocele [16]. Abnormalities of the anterior (cystocele), 
middle (vaginal vault) and posterior compartment (rectal descent) were estimated as a descent at $90^{\circ}$ to the PCL. An enterocele was defined as descent of the peritoneum containing small bowel or the sigmoid below the PCL. Anorectal angles were measured between the longitudinal axis of the anal canal and the posterior rectal wall [16]. Rectal prolapse was noted dividing prolapse into intrarectal (intussusception) and external. A typical preoperative MRD of a rectocele patient is displayed in Fig. 1.

\section{Surgery}

In all patients, a mesh-free perineal anterior repair was performed [13]. After a semicircular incision, the rectovaginal septum was dissected up to the upper end of the rectocele. The bulbocavernosus and levator muscles were prepared and sutured together with connective tissue in the midline. This approach allows a simultaneous overlapping sphincter repair in event of a sphincter defect, which was the case in three patients in this study.

\section{Radio-clinical correlation}

The clinical scores for faecal incontinence and QoL were correlated to rectocele size pre- and postoperatively and

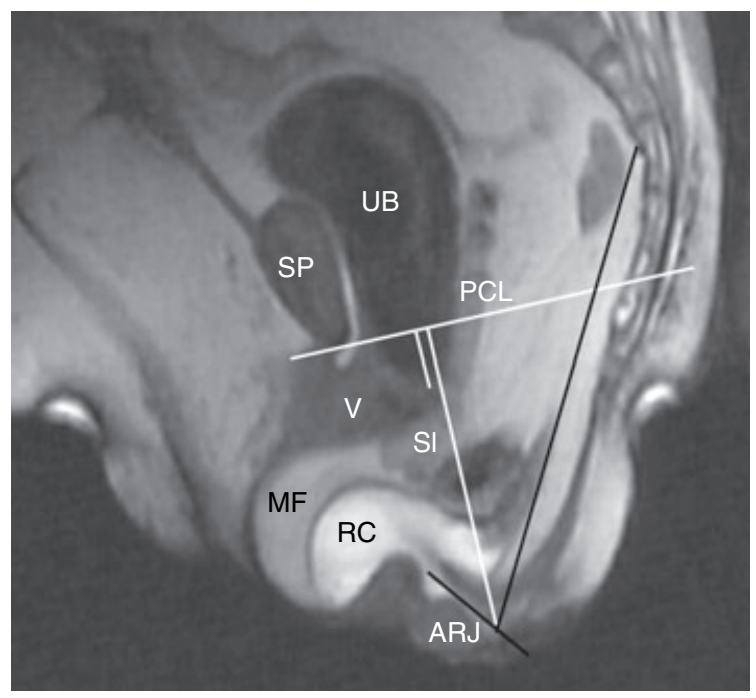

Figure I Preoperative magnetic resonance defecography findings in a rectocele patient Midsagittal magnetic resonance (MR) images obtained in a 77-year old female patient posthysterectomy with defecatory pain and stool fragmentation. On the Tlweighted $\mathrm{MR}$ image with the patient sitting during defecation, a large anterior rectocele (RC) that causes incomplete evacuation is seen. The large enterocele contains mesenteric fat (MF) and small intestine (SI). The relative descents of the urinary bladder (UB) and the anorectal junction (ARJ) are documented (vertical lines) with respect to the inferior pubococcygeal line (PCL) joining the inferior border of the symphysis pubis $(\mathrm{SP})$ and the last coccygeal joint. $\mathrm{V}$, vagina. to the change in rectocele size. Furthermore, the clinical symptom of incomplete evacuation and the corresponding radiological sign of trapped contrast dye were correlated pre- and postoperatively.

\section{Statistical analysis}

The McNemar test was used assessing binominal data, whereas the Wilcoxon test was employed for analysis of numeric data, defining statistical significance as usual at a level of 0.05 . Correlation was tested according to Spearman.

\section{Results}

\section{Did clinical findings improve after surgery?}

Preoperative symptoms were present in each patient, ranging from 6 months up to 10 years prior to the operation and are presented with the postoperative symptoms indicated in Table 1. Four of eight and five of seven patients, respectively, showed improvement after surgery with respect to pain and incomplete evacuation. However, pain and incomplete evacuation were new postoperative symptoms in one patient each. Seven patients $(50 \%)$ complained of new postoperative dyspareunia. Ten patients reported a better QoL after surgery, while three felt worse (Fig. 2). Overall QoL improved significantly after surgery from a median score of 90 (range 38-106) to a median score of 105.5 (range 29133; $P=0.02)$. With one exception, all patients had some degree of preoperative incontinence (median Wexner-score of 8 , range 0-20). Postoperatively, nine patients had an improved score by 2 points or more (Fig. 3) with a normal continence in three patients (median Wexner-score 4.5; range $0-18 ; P=0.023$ ). The urine incontinence score did not change significantly (pre- and postoperative median Hanley-score of 2).

\section{What are the pre- and postoperative MRD findings?}

Rectoceles significantly decreased in size in all patients as a result of surgery [median $37 \mathrm{~mm}$ (range 30-48) vs $12 \mathrm{~mm}$ (range $0-42) ; P=0.004$ ] and qualitative incomplete evacuation was also significantly decreased (10 vs 4 , $P=0.031)$. Eleven from 12 enteroceles $(92 \%)$ and two from four external prolapses $(50 \%)$ were also corrected by the surgery of the anterior septum. Anorectal angles remained unchanged. Descent of the anterior and middle compartment could be reduced significantly, however, the posterior compartment was not significantly elevated. MRD findings are summarized in Table 2 . 


\section{Does a correlation exist between clinical symptoms/ scores and the morphological (MRD) findings?}

There was a strong relationship between the clinical sensation of incomplete evacuation and the postoperative corresponding radiological finding of contrast dye trapping after defecation (correlation coefficient: $R h o=$ $0.822 ; P=0.001)$. In contrast, there was no correlation between the preoperative rectocele size and the severity of symptoms. Similarly, there was no correlation between the morphologic surgical correction and the postoperative symptoms.

\section{What is the surgical outcome?}

Minor complications such as haematoma $(2 \times)$ and wound infection with impaired wound healing $(2 \times)$ occurred in four patients and were all treated conservatively with success. The patients were discharged after a median hospital stay of 5 days (range 3-6). Median follow up after surgery was 16.5 (range 9-45) months.

\section{Discussion}

To our knowledge, this is the first attempt to analyse MR defecography in the pre- and postoperative assessment of rectocele surgery and to correlate radiological and clinical findings.

In the present study, the size of the rectocele was significantly reduced by surgery. Similar 'structural defect repair rates' have been reported by others $[9,13,15]$ using conventional defecography for assessment. Additional information provided by MRD in this study included the diagnosis of enterocele, pelvic floor insufficiency and sphincter defects. The enteroceles were also corrected by surgery and the anterior and middle compartment could be significantly elevated. As expected, no significant

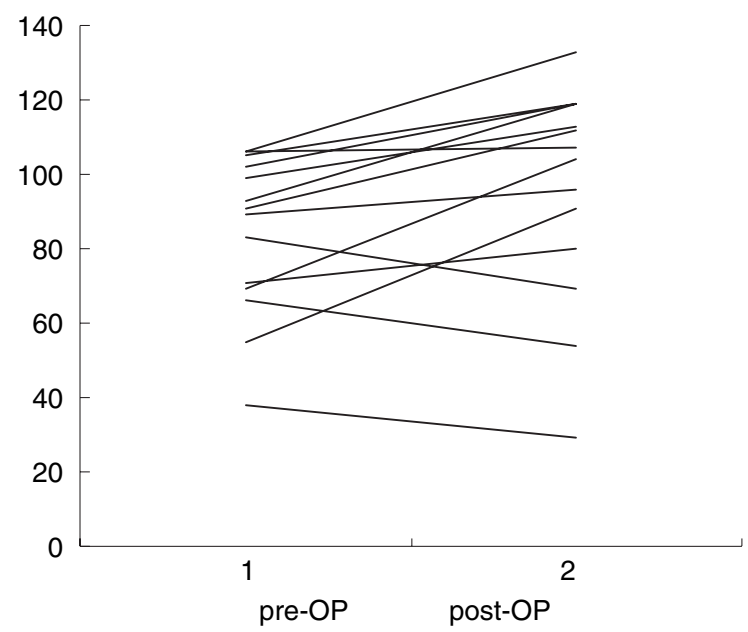

Figure 2 Pre- and postoperative scores for quality of life (Eypasch). The Eypasch-score grades quality of life (QoL) in patients with problems related to the GI-tract from 0 up to 144 (perfect QoL). Ten patients had a better QoL after surgery, while three felt worse. Overall QoL improved significantly $(P=0.02)$ by surgery from a median score of 90 (range 38-106) to a median score of $105.5(r: 29-133)$.

changes in the posterior compartment and in the anorectal angles were observed as this area is not influenced by the anterior surgical approach. MRD is advantageous in defining the interactive dynamic activity of all three compartments and represents a reliable all-inone diagnostic tool in the preoperative assessment of patients with rectoceles, even though costs are higher compared with conventional defecography [20,21].

We found a significant correlation between the clinical sensation of incomplete evacuation and the corresponding radiological finding of contrast dye trapping after defecation. None of the other MRD findings was of prognostic value or could objectively confirm clinical outcome. This is in accordance with the published data

\begin{tabular}{lllllll}
\hline $\begin{array}{l}\text { Symptoms, } \\
n(\%)\end{array}$ & $\begin{array}{l}\text { Pre-OP } \\
\text { total }\end{array}$ & $\begin{array}{l}\text { Post-OP } \\
\text { resolved }\end{array}$ & $\begin{array}{l}\text { Post-OP } \\
\text { unchanged }\end{array}$ & $\begin{array}{l}\text { Post-OP } \\
\text { new }\end{array}$ & $\begin{array}{l}\text { Post-OP } \\
\text { total }\end{array}$ & $P$-value \\
\hline Pain & $8(57)$ & 4 & 4 & 1 & $5(36)$ & 0.375 \\
$\begin{array}{l}\text { Incomplete } \\
\text { evacuation }\end{array}$ & $7(50)$ & 5 & 2 & 1 & $3(21)$ & 0.219 \\
$\begin{array}{l}\text { Digitation } \\
\text { Soiling }\end{array}$ & $5(36)$ & 2 & 3 & 1 & $4(29)$ & 1.000 \\
Obstipation & $3(29)$ & 2 & 2 & 3 & $5(36)$ & 1.000 \\
Dyspareunia & $0(0)$ & 1 & 2 & 0 & $2(14)$ & 1.000 \\
\hline
\end{tabular}

The main symptoms are listed pre- and postoperative as total number (\%). Additionally postoperative changes are quoted (resolved, new) as well as the unchanged symptomatic patients. The $P$-value refers to the total number of patients with symptoms pre- $v s$ postoperatively.

Table I Clinical symptoms. 


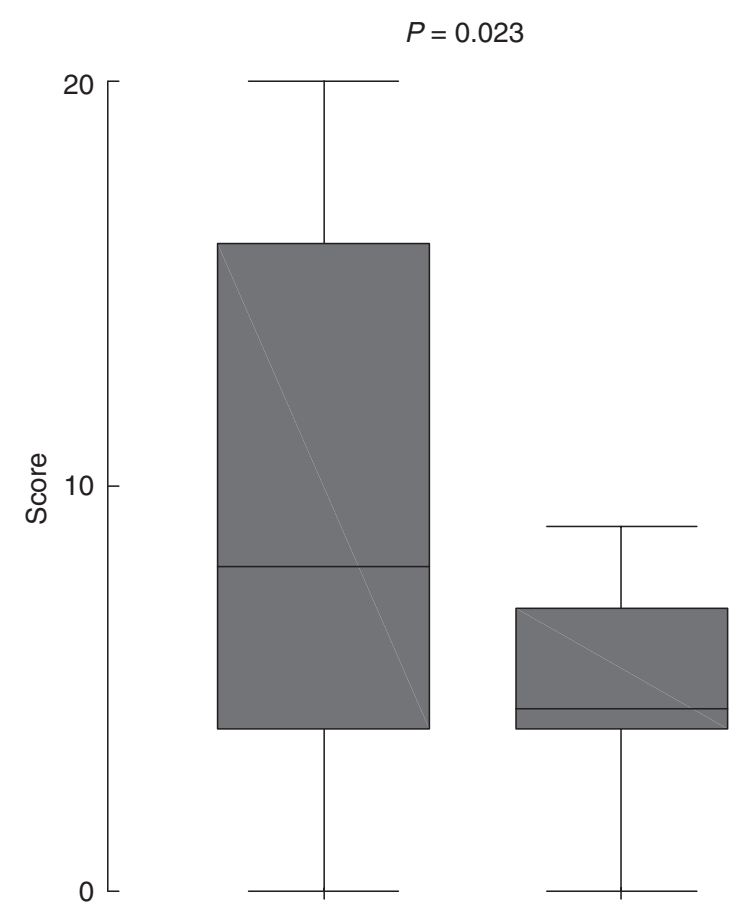

Figure 3 Pre- and postoperative scores for faecal incontinence (Wexner). The Wexner-score grades faecal incontinence from normal continence $(0)$ up to a complete incontinence [20]. The median Wexner-score (transverse line) was significantly improved by surgery from 8 (range $0-20$ ) preoperative to 4.5 (range $0-18$ ) postoperative $(P=0.023)$. The upper and lower line are drawn at the lowest and highest data values. The two lines that form the box are drawn at the 25 th and 75 th percentile.

on conventional defecography. Van Laarhoven et al. [9] found no clinical difference between patients with major and minor reduction of rectocele size. In another study, van Dam et al. [22] demonstrated the postoperative disappearance of the rectocele on defecography but the clinical success rate was only $60 \%$ with no correlation between radiological findings and clinical outcome. The same authors evaluated patients with poor outcome after rectocele repair and found neither radiological findings like rectocele size or contrast dye trapping, nor clinical symptoms like digitation or incomplete evacuation to be prognostic factors [23]. Others observed a correlation between duration of rectal emptying and incomplete evacuation and rectocele depth $[1,23]$. The lack in radioclinical correlation indicates a complex and not fully understood pathophysiology of rectoceles. Some authors divide rectoceles based on physiological differences and underlying genital prolapse into 'distension' (type I) and 'displacement' (type II) rectoceles [3]. However, the impact of this classification on surgical outcome remains controversial. Interestingly, we observed no difference among seven patients posthysterectomy (50\%) compared with the others regarding symptoms, radiological findings and outcome.

The success rate of rectocele repair varies in the literature between $71 \%$ and $92 \%$ [3,13-15]. Postoperative dyspareunia is reported to occur in $22-50 \%$ of the patients after rectocele repair $[3,13,15,24]$. Overall, QoL was significantly improved after surgery on the patients in our study. However, new postoperative dyspareunia was seen in $50 \%$ of the patients. Dyspareunia is obviously a major problem after anterior repairs $[3,24]$ and is generally not taken into account in QoL questionnaires such as the Eypasch score. Several groups suggest that a less invasive defect-specific repair might be of importance [3]. However, patient selection is heterogeneous, operation technique is inconsistent, prospective data is limited and long-term follow up is pending. Promising new techniques abstain completely from creating piling sutures in the rectovaginal space. The stapled transanal rectum resection (STARR)-procedure aims to correct the internal rectal prolapse as
Table 2. Magnetic resonance defecography (MRD) findings

\begin{tabular}{lccc}
\hline MR measurements & $\begin{array}{l}\text { Pre-OP median } \\
\text { (range) }\end{array}$ & $\begin{array}{l}\text { Post-OP median } \\
\text { (range })\end{array}$ & $P$-value \\
\hline Rectocele size & $37(30-48)$ & $12(0-42)$ & 0.004 \\
Enterocele size $n=12$ & $44(20-70)$ & $18(0-43)$ & 0.002 \\
Anterior compartment descent & $22(0-41)$ & $20(0-27)$ & 0.018 \\
Middle compartment descent & $19(0-52)$ & $10(0-45)$ & 0.004 \\
Posterior compartment descent & $62(47-105)$ & $59(25-86)$ & 0.080 \\
Anorectal Angle (ARA) & $110(96-136)$ & $109(92-128)$ & 0.381 \\
$\quad$ rest (degree) & $90(77-136)$ & $89(27-127)$ & 0.323 \\
ARA contraction & $131(109-147)$ & $126(109-148)$ & 0.207 \\
ARA evacuation &
\end{tabular}

Pre- and postoperative MRD findings are listed as median values (range) with the respective $P$-value. The rectocele- and enterocele-size as well as the descent of the anterior, middle and posterior compartment were measured in $\mathrm{mm}$, the angles are given in degree. 
the real cause of outlet obstruction [25], while the external pelvic rectal suspension (EXPRESS)-procedure combines a collagen patch with a rectal suspension to the pubis [26].

The indication for surgery is still controversial and restricted to symptomatic patients. Frequently applied criteria are rectocele size, vaginal bulge and vaginal digitation $[3,14]$. Functional abnormalities, especially slow transit constipation have to be excluded [2,27]. The relatively low case number in our study is explained by a selective indication to surgery based on strict criteria and also because of the prospective study design. However, 14 from a total of 16 patients $(88 \%)$ consented to participate in our study thereby eliminating selection bias. Furthermore, all of them had a complete pre- and postoperative evaluation.

We conclude that anterior levatorplasty significantly improved QoL in patients with symptomatic rectocele. Postsurgical correction of rectoceles is accurately documented by MRD. Furthermore, a significant elevation of the anterior and middle compartment and significant correction of enteroceles was visualized. However, only moderate correlation between morphologic and clinical improvements was observed. Nevertheless, for the reasons discussed in this paper, MRD is a valuable tool to preoperatively assess patients with rectocele.

\section{References}

l Siproudhis L, Ropert A, Vilotte J et al. How accurate is clinical examination in diagnosing and quantifying pelvirectal disorders? A prospective study in a group of 50 patients complaining of defecatory difficulties. Dis Colon Rectum 1993; 36: 430-8.

2 Segal JL, Karram MM. Evaluation and management of rectoceles. Curr Opin Urol 2002; 12: 345-52.

3 Zbar AP, Lienemann A, Fritsch H, Beer-Gabel M, Pescatori M. Rectocele: pathogenesis and surgical management. Int $J$ Colorectal Dis 2003; 18: 369-84.

4 Shorvon PJ, McHugh S, Diamant NE, Somers S, Stevenson GW. Defecography in normal volunteers: results and implications. Gut 1989; 30: 1737-49.

5 Olsen AL, Smith VJ, Bergstrom JO, Colling JC, Clark AL. Epidemiology of surgically managed pelvic organ prolapse and urinary incontinence. Obstet Gynecol 1997; 89: 501-6.

6 Shafik A, El-Sibai O, Shafik AA, Ahmed I. On the pathogenesis of rectocele: the concept of the rectovaginal pressure gradient. Int Urogynecol J Pelvic Floor Dysfunct 2003; 14: 310-5; discussion 315 .

7 Pfeifer J, Oliveira L, Park UC, Gonzalez A, Agachan F, Wexner SD. Are interpretations of video defecographies reliable and reproducible? Int J Colorectal Dis 1997; 12: 6772 .

8 Halligan S, Bartram CI. Is barium trapping in rectoceles significant? Dis Colon Rectum 1995; 38: 764-8.
9 Van Laarhoven CJ, Kamm MA, Bartram CI, Halligan S, Hawley PR, Phillips RK. Relationship between anatomic and symptomatic long-term results after rectocele repair for impaired defecation. Dis Colon Rectum 1999; 42: 204-10; discussion 210-1.

10Schoenenberger AW, Debatin JF, Guldenschuh I, Hany TF, Steiner P, Krestin GP. Dynamic MR defecography with a superconducting, open-configuration MR system. Radiology 1998; 206: 641-6.

11 Fletcher JG, Busse RF, Riederer SJ et al. Magnetic resonance imaging of anatomic and dynamic defects of the pelvic floor in defecatory disorders. Am J Gastroenterol 2003; 98: 399411.

12 Lamb GM, de Jode MG, Gould SW et al. Upright dynamic MR defaecating proctography in an open configuration MR system. Br J Radiol 2000; 73: 152-5.

13 Boccasanta P, Venturi M, Calabro G et al. Which surgical approach for rectocele? A multicentric report from Italian coloproctologists. Tech Coloproctol 2001; 5: 149-56.

14 Murthy VK, Orkin BA, Smith LE, Glassman LM. Excellent outcome using selective criteria for rectocele repair. Dis Colon Rectum 1996; 39: 374-8.

15 van Dam JH, Huisman WM, Hop WC, Schouten WR. Fecal continence after rectocele repair: a prospective study. Int $J$ Colorectal Dis 2000; 15: 54-7.

16 Roos JE, Weishaupt D, Wildermuth S, Willmann JK, Marincek B, Hilfiker PR. Experience of 4 years with open MR defecography: pictorial review of anorectal anatomy and disease. Radiographics 2002; 22: 817-32.

17 Jorge JM, Wexner SD. Etiology and management of fecal incontinence. Dis Colon Rectum 1993; 36: 77-97.

18 Hanley J, Capewell A, Hagen S. Validity study of the severity index, a simple measure of urinary incontinence in women. Bmj 2001; 322: 1096-7.

19 Eypasch E, Williams JI, Wood-Dauphinee S et al. Gastrointestinal Quality of Life Index: development, validation and application of a new instrument. Br J Surg 1995; 82: 216-22.

20 Matsuoka H, Wexner SD, Desai MB et al. A comparison between dynamic pelvic magnetic resonance imaging and videoproctography in patients with constipation. Dis Colon Rectum 2001; 44: 571-6.

21 Dvorkin LS, Hetzer F, Scott SM, Williams NS, Gedroyc W, Lunniss PJ. Open-magnet MR defaecography compared with evacuation proctography in the diagnosis and management of patients with rectal intussusception. Colorectal Dis 2004; 6: $45-53$.

22 van Dam JH, Ginai AZ, Gosselink MJ et al. Role of defecography in predicting clinical outcome of rectocele repair. Dis Colon Rectum 1997; 40: 201-7.

23 van Dam JH, Hop WC, Schouten WR. Analysis of patients with poor outcome of rectocele repair. Dis Colon Rectum 2000; 43: 1556-60.

24 Boccasanta P, Venturi M, Cioffi U et al. Selection criteria and long-term results of surgery in symptomatic rectocele. Minerva Chir 2002; 57: 157-63.

25 Boccasanta P, Venturi M, Salamina G, Cesana BM, Bernasconi F, Roviaro G. New trends in the surgical treatment of 
outlet obstruction: clinical and functional results of two novel transanal stapled techniques from a randomised controlled trial. Int J Colorectal Dis 2004; 19: 359-69.

26 Williams NS, Dvorkin LS, Giordano P et al. EXternal Pelvic REctal SuSpension (Express procedure) for rectal intussus- ception, with and without rectocele repair. Br J Surg 2005; 92: 598-604.

27 Johansson C, Nilsson BY, Holmstrom B, Dolk A, Mellgren A. Association between rectocele and paradoxical sphincter response. Dis Colon Rectum 1992; 35: 503-9. 